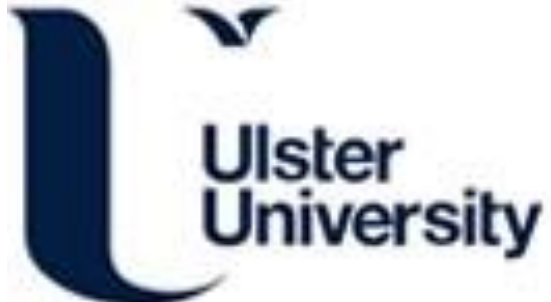

\section{Spheres of Practice for the Co-design of Wearables}

Fairburn, S., Steed, J., \& Coulter, J. (2016). Spheres of Practice for the Co-design of Wearables. Journal of Textile Design Research and Practice, 4(1), 85-109. https://doi.org/10.1080/20511787.2016.1255445

Link to publication record in Ulster University Research Portal

\section{Published in:}

Journal of Textile Design Research and Practice

\section{Publication Status:}

Published online: 12/12/2016

DOI:

10.1080/20511787.2016.1255445

\section{Document Version}

Author Accepted version

\section{General rights}

Copyright for the publications made accessible via Ulster University's Research Portal is retained by the author(s) and / or other copyright owners and it is a condition of accessing these publications that users recognise and abide by the legal requirements associated with these rights.

\section{Take down policy}

The Research Portal is Ulster University's institutional repository that provides access to Ulster's research outputs. Every effort has been made to ensure that content in the Research Portal does not infringe any person's rights, or applicable UK laws. If you discover content in the Research Portal that you believe breaches copyright or violates any law, please contact pure-support@ulster.ac.uk. 
Spheres of Practices for the Co-Design of Wearables

Sue Fairburn, Josie Steed and Janet Coulter

Sue Fairburn (Corresponding Author)

Lecturer in Design Futures, Design Researcher

Gray's School of Art, The Robert Gordon University

Aberdeen, Scotland UK AB10 7QD

s.fairburn@rgu.ac.uk

Josie Steed

Course Leader, Fashion \& Textile Design, Design Researcher

Gray's School of Art, The Robert Gordon University

Aberdeen, Scotland UK AB10 7QD

j.steed@rgu.ac.uk

Janet Coulter - Ulster University

Senior Lecturer, Fashion Design

Belfast School of Architecture, Ulster University

Belfast, Co. Antrim, BT15 1ED

jm.coulter@ulster.ac.uk

\section{Acknowledgments:}

The authors wish to acknowledge the support of multiple agencies who provided funding for the various projects that inform this research, including the Scottish Academy of Fashion, the Arts and Humanities Research Council (AHRC), and the Centre for Speckled Computing at the University of Edinburgh.

\section{Biographies:}

Sue Fairburn is Lecturer in Design Futures and Contextual and Critical Studies at Gray's School of Art. Her research interests are in extreme environments, design for social innovation, and interdisciplinary research collaborations (across the Natural and Social Sciences and Design) as informed by her post-graduate degrees in Environmental Physiology and Environmental Design. S.fairburn@rgu.ac.uk

Josie Steed is Course leader for Fashion \& Textile Design at Grays School of Art, The Robert Gordon University. Her research interests include the development of smart textiles through interdisciplinary collaboration across design, social sciences and engineering. J.steed@rgu.ac.uk

Janet Coulter is Senior Lecturer in Fashion Design at Ulster University and Faculty Director of Academic Enterprise and Innovation. She holds an MBA, MSc. in Multimedia, and a Post Graduate Diploma in Higher Education. Her current PhD research is in the field of wearable technology in fashion to support emotional wellbeing. im.coulter@ulster.ac.uk

\section{This work was supported by multiple agency grants:}

- Molecular Imprinted Textiles and Future Textile Visions were supported by the Scottish Academy of Fashion, who receive funding from the Scottish Funding Council.

- Second Skin was supported by the Arts and Humanities Research Council under grant AH/K000640/1.

- Design Specks was a collaborative teaching/research project supported by the Centre for Speckled

Computing at the University of Edinburgh.

Word Count: approx. 7450 


\section{Abstract:}

As expectations within the area of smart textiles increasingly become informed and driven by technological developments, the disciplinary boundaries and relationship between user and technological innovation will unavoidably transform. The authors venture that new paradigms of collaborative practice will inevitably develop between design and science, to more fully realise both the opportunities and contexts that wearable textiles offer. Drawing on previous work by the authors namely Molecular Imprinted Textiles (MIT - 2009/10), Future Textile Visions (FTV - 2010/11); Design Specks: Connecting People with Speckled Computing (2012/13); Second Skin (2013/14), and The $S^{* * *}$ Word: Designing the Empathic Underwardrobe (2014), a model is proposed to more clearly understand and navigate between design, technology and application, and more importantly, between our cultural understanding of the user and the wearer.

This paper reflects on a series of projects that inform a methodological approach: a process of asking questions; developing scenarios; exploring materials and making; generating concepts and building prototypes. Each project involved collaborations between Design, Academics, Users and Industry, and a form of co-design, where knowledge exchange was central, design was the intermediary, and the goal was to understand the drivers and the stakeholders. Simultaneously, this research sought to better understand and communicate the development of more empathic textile and fashion artifacts, and solutions. Co-design in this context is seen as a core approach to shifting the balance from technology as merely adjunct, or as a 'hook' for marketers and users, to a more informed and harmonised position, where technology sits proximally and comfortably. The notion of interdisciplinary understanding, which tracks across domains of Product, Fashion and Textiles, presents an approach where the application is still emerging. Through analysis of this progressive series of projects, the authors suggest that there is an opportunity to explore the inherent connectedness that textiles might offer for the integration and embedding of technology within material as a means to embrace these affordance opportunities. Central to this notion is the realisation of opportunities arising from dialogue and collaborative making (i.e. co-design), and for exploring the transformative notions of the user and the wearer.

This paper led the authors to pose a set of questions that align to a four stage design process: Research, Define, Develop, Reflect, to frame findings and insights, and to outline the potential for future opportunities of working with technology to achieve the making and wearing of desirable materialisations on the body.

Keywords: Wearables, Smart Textiles, Co-Design, Design Methods, Digital Fashion, Prototyping, Product

\section{Introduction}

Traditionally, designers within the textile industry have focused on aesthetics, function and the tacit experience of constructed, soft material solutions (Igoe 2010). Product designers work in a complementary space, where they seek to understand user needs, desires and expectations and realise the affordances that technology brings to artefacts. The authors are interested in the space between these practices and the opportunity to explore the inherent willingness that textiles offer, and to embrace these affordances when worn on the body, leading to concepts that Woolley (2005) refers to as the "product unplugged."

The research scope for this paper is within the field of empathic wearable solutions that emerge from a co-design approach and in doing so, attempts to meet the needs of the user and the wearer. The drivers for research in this field are strong where textiles can provide both passive and active benefits to wearers and can integrate technology effectively within clothing. Textiles inherent tacit and tactile characteristics humanize technology and are therefore a perfect medium for exploring wearables in a range of contexts.

Central to this paper is the need to establish an understanding of the authors' use of the terms: 'user' and 'wearer'. Users are those with a certain need for a product that addresses a particular function and does so in a way that is intuitive and consistent. The proficient Product Designer Dieter Rams cites "the user", "usefulness" and "use" in four of his 10 principles for good design (Lovell, 2011). Thus, needs, function, and functionality are key concepts underlying design intentions. On the other hand, wearers refer to those who don a covering or feature object for purposes of adornment, style, identity or desire. Bugg (2009) comments on the wearer in her research into the designer, wearer and viewer, and proposes a model that explores the concept of the wearer as central to fashion thinking, driven by context and concept rather than trends, commerce and market. Gwilt (2013) expands on the importance of the wearer in her work on sustainability in textiles, where she identifies and stresses the significance of the wearer - in fact she draws 'use' into the conversation about the development of "...garments that can assist the wearer to extend the life cycle of a garment during the use phase." 
Whilst these definitions of user and wearer are bound to provoke discussion, we propose these definitions to help explore ways to transform design between cultures and context, and to inform methodologies that sit across the disciplines and bridge the gaps - to develop design solutions that sit between users and wearers, between function and desire, between functionality and identity - for wearables. For example, previously some performance wear solutions (i.e. for sports, extreme environments, etc.) were seen as being outside the fashion market, but through adoption as fashion statements, they have been repositioned and repurposed, which supports the position that the identity of designs can 'alter and respond' - that is what fashion does - the driver is the wearer.

New paradigms of practice are required with different types of collaboration between design and science disciplines and combined methodologies to fully exploit different contexts for textiles with enhanced technological capabilities. Miniaturization on a nano-scale, together with sensor developments, have made possible the concept of a 'smart skin' where soft-engineered products for the body can produce a ubiquitous computerized outer layer which can respond and monitor changes in the body.

Fiona Dieffenbacher's work on Fashion Thinking supports such a shift in practice and further advocates the importance of designers to rethink their design process so to be "driven by their own particular perspective and instinct" (Dieffenbacher, 2013:10). We propose that the emergence of designs in this area have resulted from various approaches, with two that are more central to our practices: speculative and empathic, which we discuss in more detail before exploring the transformative aspects of wearables relevant to our research. Through our mapping activities carried out to date, we developed a draft framework that positions the wearer and the user as central elements of transformative design - where notions of wearer and user are key to understanding adoption and desirability. In doing so, we explore the transformative culture of fashion and textile design alongside the transformative concept of product design, and identify the intersections and insights this raises.

\section{The Mismatch between Textiles and Technology}

Recent market research by a UK based consultancy predicts that over 70 million smart wearable devices for fitness and wellbeing activities will be in use globally by 2018 . There is debate over what the 'thing' is exactly and despite rising sales the devices themselves have shown limited uptake with consumers who show a growing awareness of the technology and the possibilities it offers to support healthy lifestyles (Moar 2014).

Opportunities for clothing as an interface are clearly apparent; it is intimate, mobile, personal and in some instances protective, and it enables body-sensing measurements to be transported and ubiquitously embedded within everyday life. However, current fashion and textiles are not meeting the physical and psychological requirements for those seeking wearable smart products (O'Mahoney 2011). Neither technologists nor designers working singularly in their own area are able to fully understand how to develop the opportunities that wearables present. However, one of the major challenges in the development of commercially adopted smart textile solutions is the gap identified between the designer and the technologist (Dunne, 2010), where at present the main driver of research is technology based rather than through design (Hildebrandt et al. 2015), yet the technology needs to be seamlessly married with design aesthetics and comfort for the wearer. New areas of research concerned with this gap are emerging, for example "The Wearable Technology Lab" at the University of Minnesota's College of Design, under the directorship of Dr Lucy Dunne, who has written extensively on the field of smart textiles within clothing design. Meeting the opportunities requires new thinking coupled with interdisciplinary design culture, methods and technologies to fully realise our wearable future (Oliver et al. 2009).

Using textiles as input devices is a relatively new research field where the adoption of soft product solutions enables other types of users, particularly user groups with specific requirements or desires, or sub-cultures. When technology and design are developed separately, the conflicts only become obvious when used in context. As a result, the commercial adoption is often not forthcoming, as the wearer's comfort, identity and style have to be the main priorities. The challenge here is clearly for technology and design to meet the needs of the user as the wearer.

The gap between technology and design seems obvious to designers, though sometimes less so to technologists and engineers. Finding new ways for these two fields to connect and intersect will catalyse the opportunities that exist in the overlap between the disciplines by uniting their interests and efforts. The intersections will require a balance between the prerequisites for these two distinctly different practices and their approaches to design. "Intersections" were the focus of the recent FutureScan3 Conference ${ }^{1}$, hosted by Glasgow School of Art, which recognised the transient nature of the fashion and textile industry and sought to explore and inform the nature of these intersections. The author's (Steed

1 The FutureScan3 conference (11-12 November 2015) sought to explore the intersecting nature of practices and identities within Fashion and Textile Design. http://www.ftc-online.org.uk/futurescan-3/ 
and Fairburn, 2016) contribution to the conference focussed on programmes and prototypes - specifically exploring new ways of working with technology and the different outcomes that arose, which led to shared insights into the 'disconnects' between academia and industry, design and technology.

Our expectations of technology are fed by the successes of products in our everyday routines. These are the examples that fulfill our needs, such as the clocks that automatically sync with time zones and the cars that guide us to our destinations. They require no alterations to our habits and function seamlessly with our environments. Similarly, there are technical textiles that respond to environmental changes and alter their function without intervention on the wearer's part - these textiles are truly smart. However, alongside these examples of wearables that have reached a level of consumer acceptability and thus, commercial successes, many have failed and become artifacts of technological demise.

Designers alone cannot solve the challenges and new methods of bringing disparate disciplines together are essential, but this transformation is not without challenges. Different approaches to problem solving and dissimilar languages associated with disciplines make working together a complex task. Building strategic relationships and finding commonality between fashion and technology is crucial to the development of the emerging field 'wearable technologies'. It is timely for designers to develop tacit knowledge in 'computational' and 'science' elements to make them a truly interdisciplinary asset to a team.

The interdisciplinary design process in this research respected past traditions, whilst reimagining the future for wearers. The knowledge gained at the intersections between fashion, technology, product and the human body brought greater understanding and insight to the potential function of textiles and empathic solutions associated with wearables.

\section{Speculative Design}

A number of textile and product designers are working to explore future materials and new applications of emergent technologies. The Futurescan3 conference featured the work of Carole Collet, a keynote speaker, whose work into biological principles (bio-design and bio-manufacturing) and living technology intersects science and design and is considered central in the evolution of future textiles. Key drivers for this area are new applications for textile techniques, user-driven design, and the potential for new manufacturing systems within the industry (Congdon, 2015).

This emergent area of future materials; integrated technology, products and textiles, is central to the field of speculative design. Speculative designs are those that raise the potential away from capitalist conventions and offer visionary glimpses of alternative futures. In her work on growing textiles, a project called 'Biological Atelier', Amy Congdon asks the question: What role will textile design play in the creation of biological products of the future? (Congdon, 2015) These materials and tools mean new opportunities for design; from the re-appropriation of textile skills through to the new technologies that may facilitate production. As yet, it is unclear how these meet the needs and wants of the user, aside from the obvious opportunities for consumer-driven, bespoke product solutions.

It could be presumed that this area of emergent design is still in its' youth, and that it developed from design practices that are more critical and speculative in nature. In their recent book: Speculative Everything (2013) Dunn and Raby offer a chapter entitled "A Methodological Playground" which presents a broad and highly engaging overview of the importance of going beyond logic and pragmatism. They offer a range of approaches and sources of inspiration, including utopian, dystopian, and ideas as stories. In each case they explore how ideas emerge, and how design might embrace a level of invention that feeds design's medium of materiality and artifacts. Central to their approach is the question of 'what if', as a scenariobased means to aid designers, scientists, and others collaborators, to explore an idea.

Whilst some companies are engaging in collaborations with artists and designers, such as those between Congdon (Grow your own part) and Tilbury, and Male's collaboration with car-manufacturer Infiniti (Studio XOX), much of this exploratory work is too speculative to engage industry and the benefits of creative collaboration between Industry and Academia are viewed more cautiously unless there is a clear path to commercialisation. Similarly, the concepts arising are often critical in nature and whilst they provoke discussion and help us to explore the concepts of needs, desires and functionality, they often do so at a considered distance from the working space of co-design. As a considered position, Haldane (2014) advocates for speculative design as a valuable research tool that offers the designer freedoms beyond commercialisation, and he notes that even though the outcomes may lack practical application, they often maintain a "nuanced appreciation of human needs, desires and psychology."

\section{Empathic Design}

Wearables have been enabled by the miniaturisation of electrical components and batteries, which when combined with other technologies, such as Bluetooth, facilitate the transfer and display of data. Computational technology and smart materials challenge textile traditions in terms of materiality and garment construction, and they have created a new space in design, where fashion, textiles and technology intersect, merge and generate a new typology. In the context of our research and this paper, wearables can 
reference both electrical componentry, i.e. technology, as well as empathic consideration, i.e. the user's needs and the wearer's wishes. This positioning of wearables generates a potentially complimentary space for design but it also presents designers with a challenge, as described by Baurley and Stead (2007) and one where "an understanding of a Designer's core skills is paramount."

Technology is moving towards enabling textiles to create intimate relationships with our personal data. As technology moves close to the senses, through discrete integration into clothing, a new empathic second skin is created that responds intuitively to our needs. Users begin to experience contact and connection with the digital information in the same way that they experience contact with other humans, as "priorities, preferences, and inner conflicts" (McDonagh \& Formosa, 2008). Empathic design builds emotional connections between user and product at an early stage of the development process and seeks to understand users' experiences in an attempt to discover their undiscovered needs. This approach enables designers to innovate new solutions, often for problems that users had not considered or identified. Cognitive empathy, "intellectually taking the role or perspective of another person" (Gladstein, 1983), in the design process enables designers to become "closer to the user through respectful curiosity, genuine understanding, and suspension of judgement" (McDonagh et al, 2009).

Empathic approaches sensitise designers to user's needs, affording them greater insight and personal understanding of user's interactions with products, including textiles and garments. How a product makes a person feel and how a person feels about using a product is as important as its' actual functionality (Wilkinson and De Angeli, 2014). If designers focus solely on functionality for the end user, without due consideration for empathy, they risk their products having a stigmatic appearance (Skogsrød, 2014). Products that look and feel good are more likely to achieve end user adoption and their positive effect enhances the overall experience for the user, meaning attractive things do indeed "work better" (Norman, 2012). It is difficult to quantify the impact of aesthetics, however Norman notes that as emotional beings, we all judge the appearance of products, whether consciously or unconsciously, and aesthetics should be considered an important function because of this alone.

There is an increasing need to move smart textiles beyond novelty value. Sensor-embedded garments (e-clothing) have the potential to change the meanings of clothes and create emotional relationships between garment and wearer. Emotional connections to textiles are well documented (Mottram, 2004; Stead, 2009; Lynas, 2010); however smart textiles and e-clothing create possibilities for adding new social dimensions and new ways of interacting and communicating. This exciting prospect underpinned the rationale for our collaborative research activities. Igoe prompts readers in a similar direction with her provocation; "If it is agreed that 'design and emotion' is a field ripe for input from the textile design discipline, how might this input reshape the field or vice versa?" (2010)

Designers alone cannot solve the challenges in realizing opportunities in e-clothing and smart textile products. The interdisciplinary, practice-led research we undertook offers a methodology to shift the paradigms of what design is currently to what design could become as a collaborative, transformational, empathic user experience.

\section{Transformative Design}

The overarching aim of this series of research activities was to define the potential for wearables that would inform innovative design, lead to new developments, and demonstrate how design supports the transformative process. Transformation Design (TD) is about creating the capability to design experience from a human perspective (Coughlan, 2003). The key characteristics associated with TD are comprehensively summarised by Burns et al., (2006).

TD seeks to create desirable and sustainable changes in user behaviour, through new models of innovation. It is not a new field of study, but rather a new mind-set and is concerned with building relationships to explore possibilities, rather than with designing end products. It aspires to enable rather than fulfil, through a divergent exploration of social and human needs, mediated through design, in preference to a convergent process of problem solving. The designer is the mediator, and all stakeholders are designers within a community of practice. TD enables collaboration across a community, creating a neutral environment to facilitate a range of stakeholders' views, experiences and expertise. It brings new thinking to a problem and offers a fresh dialogue for design. Its holistic approach fosters new social dimensions and creates conditions to better understand the scope of the issue and frame the problem, while leaving the canvas within the frame sufficiently expansive to allow for the fluidity of the dialogue. It goes beyond a multidisciplinary format, where stakeholders from different disciplines contribute their knowledge to solve a problem, and moves towards an interdisciplinary approach where all stakeholders become participants in the design process. TD brings about a reciprocal learning process between designers and collaborators and leads to transformative understandings (Shuler \& Namioka, 1991). The designer's power is redistributed and all participants become empowered. This was particularly important in the context of our research where we sought to build on speculative approaches and empathic methodologies and apply these to situations outside of the design discipline expertise.

Technology is changing peoples' lives exponentially without necessarily improving the way they live 
(Rosenberg, 2014) and designers should not be seduced or driven by technology, but rather be concerned with human experience and cultural transformation. However, the ambiguous nature of 'human experience' makes this challenging to define. Human experience has to become the subject of the design to enable an exchange of ideas and personal experiences between the stakeholders, and to enhance their own understanding of the subject. Reflecting on each other's transformations through experimental and often playful techniques of prototyping provides a tangible way of developing ideas and Burns et al, (2006) observes that skills become employed in non-traditional territories, often producing non-traditional design outputs.

Transformative Design in this context is about blending culture and concepts. In fashion and textiles - fashion thinking integrates an understanding of culture: i.e. the environment of the wearer, desire of the wearer, style/identity and emergent trend. In product design there is a more formalised approach to research that focuses on user behaviour and its relation to the concept of product function. Though these approaches are not distinctly different, and there are examples of similar activities and methods, the underlying intentions of transformative design is to explore ways to blend and integrate these approaches design intersections.

\section{Research Contexts}

The drivers underlying this research are contextualised by the growing complexity of human needs in a changing global society. With greater life expectancy, design innovation within this field offers substantial rewards both in terms of improving existing design solutions and also in developing new markets and economic opportunities. Twenty first century textiles combined with ubiquitous computing and nanotechnologies have considerable potential to address these new social and individual needs and provide fresh solutions for innovative products that improve the quality of life.

Our research programme sought to bring together expertise, from a range of disciplines within partner universities and established manufacturers and services within the Textiles sector. The programme approach took into consideration the breadth of human health and wellness and applied co-design methodologies so users with specialised needs could work alongside a network of experts from fashion and textiles, product design, informatics, material science and medicine. The aim of the extended group of participants was to identify a range of applications and unmet needs for technologies that could be developed in partnership with a wider range of stakeholders - informed by thinking and designing.

Design Thinking is a term that references a way of thinking, that is grounded in a human-centred approach, and draws in a set of tools that are familiar to designers, to integrate the needs of people, technology, and businesses (Brown 2008). The key to this approach is designers' sensibilities and methods. Brown positioned design thinking as bringing together what is feasible with technology, viable from a business perspective, and desirable from the perspective of human needs.

Both textile designers and fashion designers use 'design thinking' processes, however, there are distinct differences between 'textile thinking' and 'fashion thinking'. Textile designers tend to think in two dimensions, and are largely concerned with surface, rhythm, scale, repeat, tactility, and with properties and functionality. The deep tacit nature of textiles together with their inherent tactile and sensorial qualities differentiates the textile designer's area of knowledge and contribution within innovative interdisciplinary practice. Igoe (2010:8) suggests that textile practitioners contribute their tacit 'knowledge of textiles to make items aesthetic and/or haptic'. In contrast, Fashion designers think in two dimensions and are interested in the quality of form and silhouette. Fashion considers the form of the body, and its' practice is constrained by a standard set of measurements, which it ironically applies to infinite variations of non-standard measurements of the individual body. Fashion considers the ever-changing dynamicity of the moving body, whereas textiles are usually conceived as static artifacts. In addition, fashion designers' processes are often viewed as unfathomable from an outsider's perspective, where they can be described as chaotic, messy, paradoxical and often illogical with no clear beginning, middle and end (Dieffenbacher 2013). However, it is out of this 'disorder', through upending traditional lines of enquiry, through risk taking, and by challenging the norm, that innovation takes place. This chaos is fundamentally at the heart of what it is to be human where fashion has always reflected our societal needs at any particular time.

The successful adoption of fashion trends is often difficult to predict, where the wearer's individual identity, desire and appropriation are interconnected. Within fashion we refer to the end-user as the wearer, where desire and aesthetic considerations are the main drivers in clothing design and ultimately adoption. Fashion observes the adaptation of changing lifestyles influenced by environment, social communication and melds these into a garment as a self-expression of the designer's original thoughts. Fashion is consumable and changes more quickly than textiles and therefore 'fashion thinking' tends to happen at a faster pace. 'Textile thinking' often considers traditional, handcrafted process alongside technological processes, meaning the pace is slower and the timeframe is of less importance to the textile designer. Fashion frequently seeks expeditious outcomes, well suited to automated and technologically driven 
processes such as digital print, where instant results are realised. With textiles, the thinking is applied in a more methodical way, however, what is clear is that they are paradoxically different, but inextricably linked. In Ryan's chapter on Augmented dress, in her book 'Garment of Paradise', she argues that a hybrid approach to wearables is needed, where fashion, textiles, product and technology come together. She describes this as transversal or parallel practice and participatory modifications based on transitory desires. (Ryan, 2014: 230).

\section{Methodologies and Processes}

To achieve innovation in the area of applied research into future textiles and health and wellness, one must begin with an aim to avoid framing problems in such a way as to pre-determine solutions. Very often a lateral step in thinking is needed if an appropriate solution is to be achieved. Oliver et al. (2009) argues for a two-stage approach whereby the first stage focuses on product development and the second stage on the development of well-defined applications and product. When approached from this direction, the innovation horizon could be described as: Techno, Nano, 'Smart', Integrated, Wearable and Pro-active.

Each of the projects informing this overarching the body of research detailed in this paper had different agendas, however, in all of the projects, workshops were a key activity and they utilised a 'thinking through doing' approach. A broad range of generative techniques were put in place to engage stakeholders, encourage a shared understanding and drive the process, as outlined below, and in each project, co-design was central. These workshops sought to understand the importance of embedding empathic value in the design outcomes. The generative design methodologies included: scenarios and trigger words, while rapid low-fidelity prototyping was achieved using a combination of representational (i.e. foil to represent phasechange materials), and real materials prompts (conductive thread, natural textiles, manmade-textiles, conductive paint, etc.). The five projects are presented below with a brief description of each project and a reference to those aspects of the approach that are relevant to the context of this paper.

Molecular Imprinted Textiles (MIT) - 2009/10. In this initial project the underlying aim was to use specific technologies, such as laser technology and plasma treatment, to conceive of ideas for smart, memory-rich textiles capable of storing and feeding back information. It was a collaborative project based in exploring technologies, design thinking and textile techniques and involved art and design researchers from across three Scottish institutions: Herriot Watt, Edinburgh University and Robert Gordon University. Unique to this workshop was the focus on material exploration and narrative activity conducted in a group setting, where making and discussion were the focus, using traditional textile methods of making.

Future Textile Visions (FTV) - 2010/11. This second project introduced a co-design methodology and explored the potential of new textiles for health applications, appropriate to the existing textile industry, developing new value-added apparel products like garments with added functional and clothing with 'smart' attributes. The approach focussed on a response to the challenge of - how best to match up technologies with clinical needs - whilst understanding the human factors that influence behaviour and ultimately the way in which new products are perceived and adopted. This is a fair assumption reinforced by the economic market drivers that Oliver et al. (2009) identified, including; an aging population, the quality of life enhancement, and an emotional population. Inspired by a methodology proposed by Oliver et al. (2009), the FTV sessions began by using dots and lines to facilitate ideas on two-dimensional patches, which were then integrated into three-dimensional wearable concepts with form and structure. FTV generated highly visible, imaginative and emotive prototypes that abstractly interpreted and amplified human expression.

Design Specks (2012-13) explored co-design as a collaborative reaching and research project across Scotland's four art and design colleges, where the student groups were comprised of multiple design disciplines, including product design, textile design, communication design and jewelry. The approach was for design and technology to work in tandem, informed by a series of four, two-day workshops, hosted by each of the colleges, across a 9-month period. The context of the projects was 'connecting people', thus the activities worked to merge thinking about people, digital technology, and design (Arvind et al, 2013). The underlying framework, which referenced the Design Council's 'Double Diamond' model where the design process is divided into four distinct phases: Discover, Define, Develop and Deliver. Unique to this project were the latter two stages: the Develop and Deliver workshops. The 'Develop' workshop aimed to take ideas from two dimensions to three dimensions using a found object that students selected as one that embodied their 'tone of voice'. The latter element was designed to build an understanding of how the tone of voice can influence people's perception of new technology, thus influencing their adoption of technology. In the final workshop, 'Deliver', students returned to the 'wearable' aspect of their designs as they explored body archetypes through 3D body scanning, thus conveying the range of shapes and sizes and how they impact on the design of wearables.

Second Skin (2013-14) set out to explore the methodology of co-design and co-development using empathic methodologies and digital fabrication technologies - specifically rapid prototyping approaches. The first workshop considered how to facilitate a co-design process in which end-users, designers and technologists came together to explore solutions that addressed both the physical and emotional needs of 
individuals with medical issues that affect their mobility. The second set of workshops at Ulster University adopted a functional and computational approach to fashion design, and sought to explore wellness in ageing, through empathic consideration to the end user. The final prototyping workshop embedded technology discretely within clothing and products. All workshops included experts in the fields of speckled computing, rapid prototyping, product design, and textile and fashion design.

The $\mathbf{S}^{* * *}$ Word: Designing Empathic Under-Wearables (2014), was a 5-day postgraduate workshop held at the Politecnico di Milano, involving students from multiple design disciplines and a wide range of nationalities and cultural backgrounds. Whilst focusing on some group activities The $S^{* * *}$ Word specifically explored the nature of the partnership between the two distinctly different industries (underwear and technology) where representations of technology (like FTV) were used to stimulate design concepts. Initial 'discover' tasks specifically focused on rapid scenario constructs using empathic, ethnographic and anthropometric activities focusing on what it means to clothe and contain the human body. By considering both the physical (tangible) and emotive (intangible) students realised a fashion capsule collection through CAD-visualisation and form-giving prototypes. A unique feature of the $S^{* * *}$ Word was the bringing together of both product (User) methodologies, for example Function-Flow-Diagrams with fashion/textile (Wearer) methodologies of concept/mood boards.

\section{Reflections, Findings, and Positioning Insights}

Within the context of our research, improvised prototyping was developed using textiles and sensorbased technology. The scenario-based rapid prototyping was highly experimental and not concerned with a final outcome, but rather, it served as provocative and conversational iterations that moved towards realising a transformative experience for the end user. It was acknowledged that our initial prototypes would be the first of many iterations - these were quick fire interventions rather than new inventions and would be as Beucker (2015) suggests superseded by subsequent iterations in our on-going and future research. Beucker contends that consequently, transformation design is not looking for 'the' innovation but an innovation linked to the present that enables connectivity to the future. The transformative design process that the projects adopted throughout ensured that we retained an open, flexible process, which exploited the synergies between making and thinking (Hummels and Frens, 2008) and this in turn stimulates reflection for future work.

Table 1 outlines specific aspects of the various project approaches and positions them in relation to the notions of wearers and users, across the design process (approaches that are in shaded cells are discussed in further detail). This positioning relates to that of Jarche's model of "seek, sense and share" (2010), which we interpreted as: ways of seeing, ways of thinking and ways of doing. Following on from this, Figure 1 maps selected content onto a framework where the authors explore their relative positioning, again with their relevance to the wearer (fashion culture) and the user (product design concepts). 
Table 1: An overview of project practices across the design process, aligned to Wearers and Users.

(Shading denotes approaches that are in shaded cells are discussed in further detail).

\begin{tabular}{|c|c|c|}
\hline & Wearers (intentions) & Users (needs) \\
\hline Research & $\begin{array}{l}\text { Exploring subcultures of our measured lives - } \\
\mathrm{S}^{* * *} \text { Word } \\
\text { Using narratives and materialised stories to } \\
\text { embed information in textiles - MIT } \\
\text { Imagining our future selves - FTV, Second Skin, } \\
\mathrm{S}^{* * *} \text { Word }\end{array}$ & $\begin{array}{l}\text { Mapping interests in Technology \& Design } \\
\text { Mapping interests in Body \& Function } \\
\text { Mapping experience in Sector \& Supply } \\
\text { - FTV } \\
\text { Lightning talks on technology, survival and } \\
\text { the body - FTV, S }\end{array}$ \\
\hline Define & $\begin{array}{l}\text { Personal and imaginative scenarios of status } \\
\text { and self-awareness - FTV } \\
\text { Material and textural exploration - FTV, Second } \\
\text { Skin, } S^{* * *} \text { Word }\end{array}$ & $\begin{array}{l}\text { Working with user-centred design to } \\
\text { develop empathic scenarios- FTV, } \\
\text { Second Skin. } \\
\text { Thematic clustering of issues - Design } \\
\text { Speck } \\
\text { Empathic intelligence through role playing } \\
-S^{* * *} \text { Word }\end{array}$ \\
\hline Develop & $\begin{array}{l}\text { Material exploration and embellishment }- \text { FTV, } \\
\text { Second Skin, } \mathrm{S}^{* * *} \text { Word } \\
\text { Experimentation of materials on the body - FTV, } \\
\mathrm{S}^{* * *} \text { Word } \\
\text { Form giving through mannequin-based making - } \\
\text { FTV, Second Skin, } \mathrm{S}^{* * *} \text { Word }\end{array}$ & $\begin{array}{l}\text { Low fidelity representational technology } \\
\text { (2D/3D) for prototyping - FTV, Design } \\
\text { Specks } \\
\text { Exploring "tone of voice" and using } \\
\text { artifacts as relations - Design Specks } \\
\text { Rapid prototyping using a FabLab - } \\
\text { Second Skin, Design Specks } \\
\text { diagrams and user scenarios - Design } \\
\text { Specks }\end{array}$ \\
\hline Reflect & $\begin{array}{l}\text { An Exhibition of materialised wearables and prod } \\
\text { Connecting People with Speckled Computing" - }\end{array}$ & $\begin{array}{l}\text { cts and a Book "Design Specks - } \\
\text { esign Specks }\end{array}$ \\
\hline
\end{tabular}




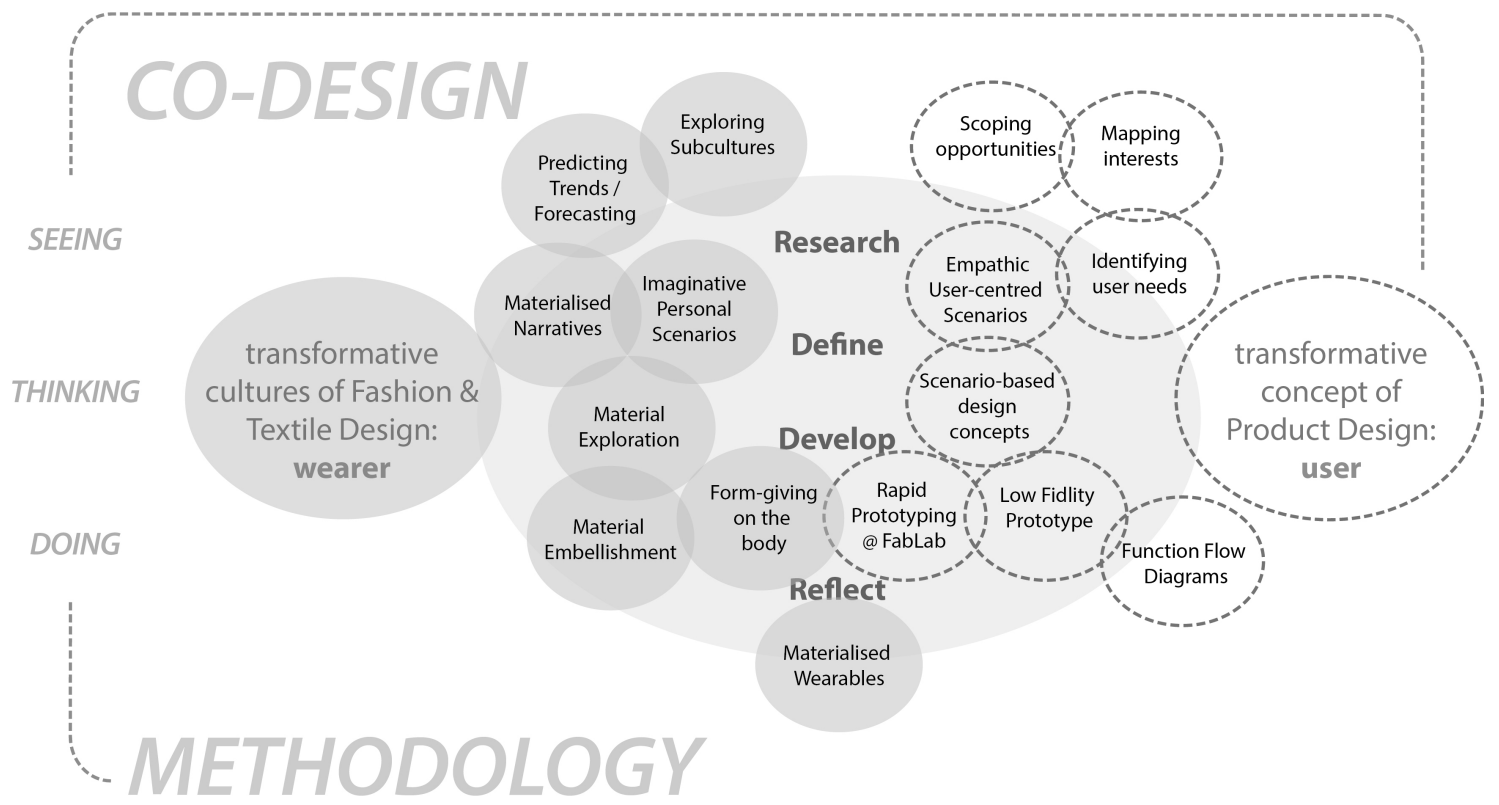

Figure 1. A working framework for mapping the spheres of co-design methodologies aligned to wearer and user.

Reflection on the projects informed a set of questions that align to the author's four-stage design process (Research, Define, Develop, Reflect) and served to frame the findings and position the insights.

> RESEARCH: What methodologies are appropriate when co-designing involves academics and industry?

$>$ DEFINE: How does adopting a co-design approach, involving the posing of scenarios and using serious play, produce concepts that can engage across stakeholder groups?

> DEVELOP: What strategies encourage dynamic transformative design?

$>$ REFLECT: Why is an intersecting set of design-led practices important in the development of new wearables?

A selection of project exemplars have been mapped onto the first three questions to help frame the insights that emerged from the projects. Owing to its' reflective nature, the final question is addressed in the Discussion section.

$>$ RESEARCH: What methodologies are appropriate when co-designing involves academics and industry?

Research Mapping: The first FTV Workshop provided an opportunity to map out the areas of expertise and technologies that could inform future projects and scoped where the group saw potential market opportunities. This method helped to identify possible synergies and contributed to starting points for approaching potential industry/academic, textile-based wellness products. Mapping formed one of the main activities for recording participant and industry interests, and associated relevant expertise, for example, as they relate to the broad categories of Technology \& Design (Figure 2). A mapping activity at the start and end of the first workshop enabled the recording of the shifts in participants' interests and ideas arising from their exposure to the technologies and scenarios for applications in health and wellness. As can be seen in Figure 2, the distribution of participant's interests along the x-axis - the continuum of Function \& Aesthetics - migrated from existing technology to emergent technology, with approximately one third of the participants indicating a shift in interests over the course of the 1-day workshop. This showed growing interest in exploring emergent technology across the stakeholders - industry, academics, and designers - but this interest needs to be supported by follow-on opportunities and activities to broaden their engagement. 
Igoe's (2010) doctoral research reinforces this finding, and she cites the interest that textile designers within academia have in innovative interdisciplinarity, however, she queries what links those designers in the commercial sector with those drawn into technological innovation. She offers up the use of tacit knowledge as a required approach and encourages the making of items that are "aesthetic and/or haptic" (Igoe,

2010:p.8). Our findings and the evolving framework encourage this combination of approaches - analytical and tactic - including embodied knowledge of materials. The MIT project used a different method narratives and materialized stories. It encouraged participants to tell stories, and to consider how tacit knowledge of materials could be the key driver to informing potential interests in new applications of technology. The outcomes of the workshop were expressed through pattern, graphics and showed potential narratives linking materials and technologies ((Figure 3).

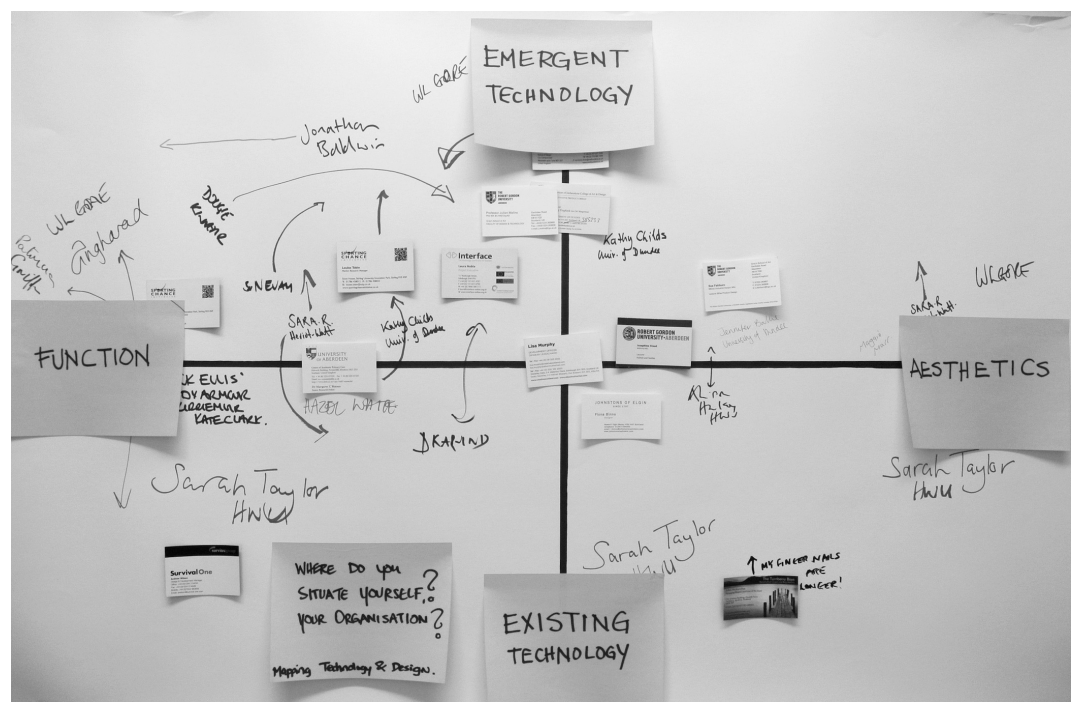

Figure 2. FTV Opportunities Map of Workshop Participants (classified as industry or academic) showing their focus at the outset of the workshop and over the course of the day, as indicated by arrows. (Image source S. Fairburn).

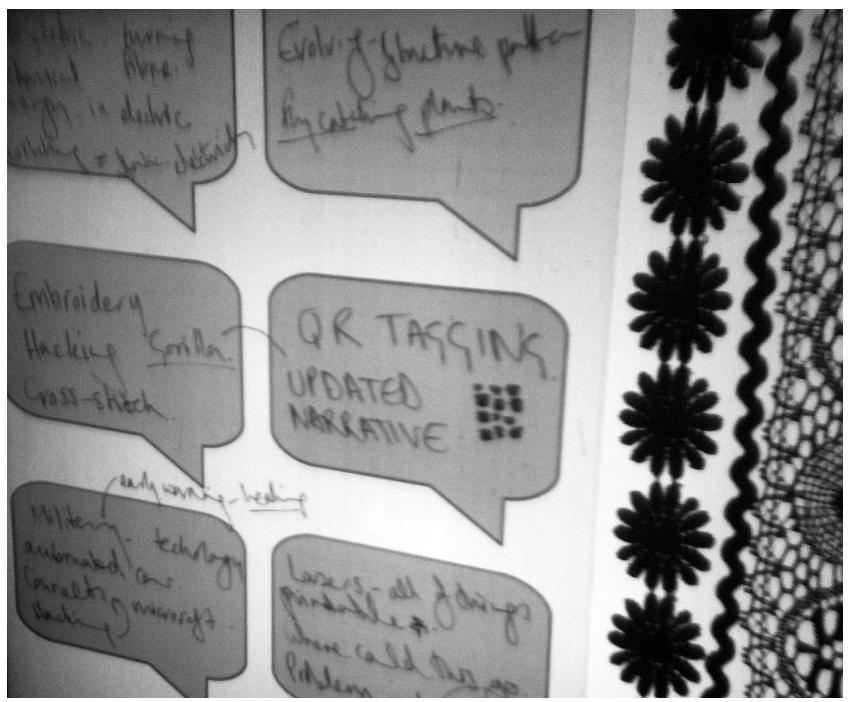

Figure 3. A capture of the MIT workshop activity showing how tacit knowledge of materials was aligned to new applications of technology. (Image source J. Steed).

> DEFINE: How does adopting a co-design approach, involving the posing of scenarios and using serious play, produce concepts that can engage across stakeholder groups?

The Second Skin project comprised a series of co-design workshops, with the knowledge from each workshop informing the next. The first workshop defined users' needs, identified through empathic design 
thinking and developed through scenario-based approaches. The users' needs were then mapped to the wearers' intentions through an exploration of textiles and technology. Koskinen \& Battarbee (2003) note the usefulness of an empathic design approach in the initial stage of developing a new product can be valuable to identify opportunities from which concepts can then be developed. Our research set out to gain an understanding of users, and their lives and routines, as a focus for developing novel products to meet their wellbeing needs and to respond empathically to their lifestyle intentions. This was achieved initially through a stakeholders' forum comprising industry, potential end users and academics from fashion, textiles, product, empathic design, science, health and human physiology. The discussions were framed by three themes based around technology, empathy for end users, and consumer-readiness.

Various co-design methods informed the authors' seeing, thinking and doing approach (Figure 1) and enabled the participants to gain new knowledge, personalize the information, and exchange ideas and experiences with others. These methods helped the authors to synthesize the formal knowledge and expertise from their co-opted experts (computer science, health and assisted living) with their own creative and user-generated knowledge (fashion textiles, product and empathic design). This rich learning was then applied to a scenario planning methodology. Scenarios are essentially stories about peoples' lives and activities. Potts (1995) comprehensively summarises their key elements as; attributing situational elements to individuals, which helps to build a picture of their world and bring understanding to their needs and desires. Scenarios are useful in grounding an idea without pre-determining an outcome, and can be left sufficiently abstract to enable designers to create more broadly around an idea. Carroll (2000) contends that the actual process of creating and designing a scenario more strongly evokes reflection than the prototype itself.

The prototypes generated by the final 'serious play' workshop were highly conceptual and unrefined, as it was recognised that the innovation exhibited by the prototypes was more important than the precision and quality of the final pieces. The outcomes served as tangible probes for forecasting future use and informing ideas for future research. This interdisciplinary, practice-led research - using a 'seeing, thinking, doing' model - informed a methodology for designing wearables and shifted the paradigms of what design is currently, to what design could become, as a transformational, empathic user experience.

\section{> DEVELOP: What strategies encourage dynamic transformative design?}

Activities from the FTV and $\mathrm{S}^{* * *}$ Word projects demonstrated how the methodologies of fashion and textile design and product design intersect, mainly through rapid prototyping and form-giving on the body or mannequin. They showed that using representations of technology in a compressed workshop (low fidelity rapid prototyping) shifted the focus from technology comprehension to concept generation. The authors maintain that when we are relieved of the expectation of making something work and understanding how it works, we can be free to speculate on how it might work and this can help us conceptualise future technological applications and potential products. Using materials that 'represented' technologies ensured that all technologies were presented as equally realisable during the abbreviated workshop activities. This design methodology was applied during the $S^{* * *}$ Word workshop (Figure 4a) and enabled students to experiment with the range of textile fabrication technologies available at the Politecnico di Milano.
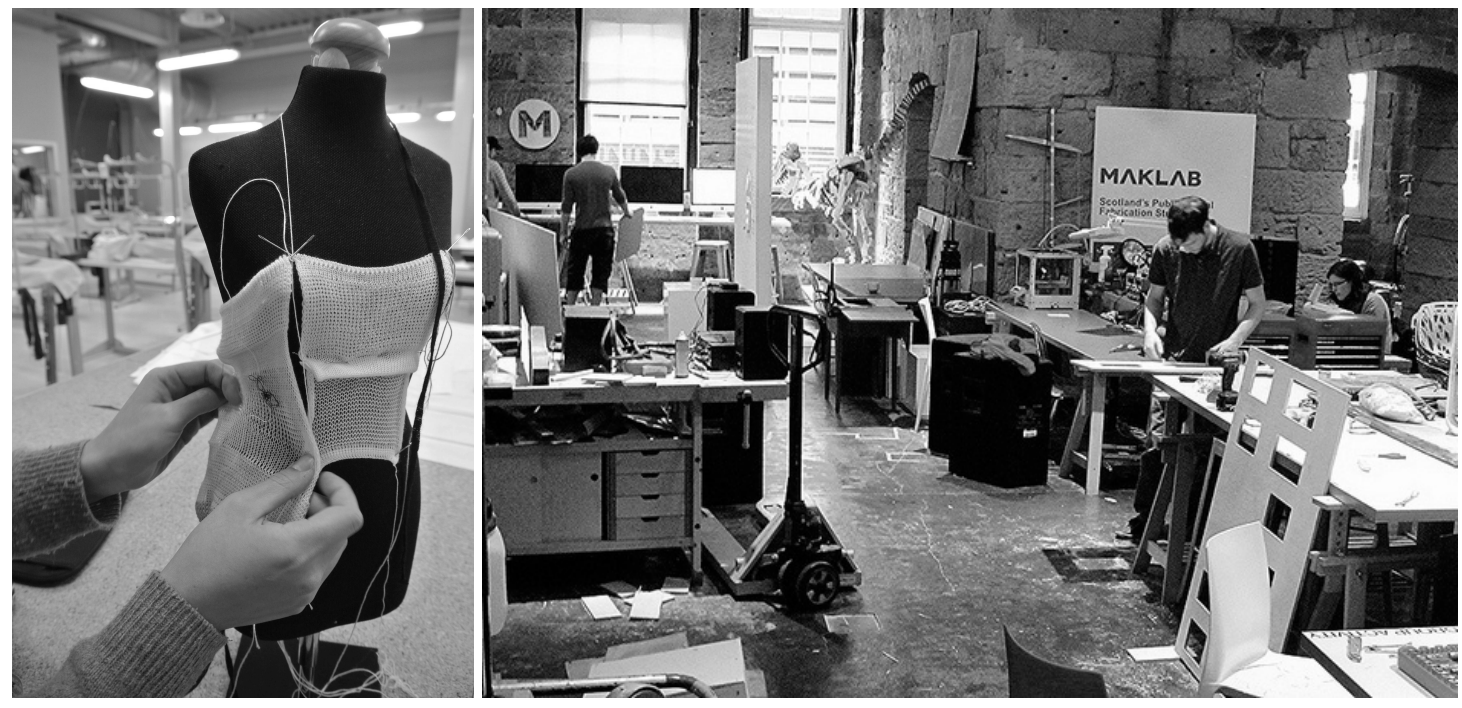

Figures 4a, b (left, right). Functional Prototyping: Digital knitting designs for the under-wardrobe project at 
the Politecnico di Milano (S*** Word) and 3D-printing design concepts at MAKLab Glasgow (Second Skin).

In comparison, Second Skin and Design Specks demonstrated that using functioning technology and digital rapid prototyping, even in a compressed workshop format, changed the focus towards actualisations. The designs that emerged from the Second Skin prototyping workshop that utilized a 'FabLab' facility (Figure 4b) were in different stages of market readiness. The prototypes were recognizable and perceptible as wearables and domestic artifacts, and though not yet fully resolved they had demonstrable potential to invite conversations with industry and users.

It was observed that the most insightful intersections were in material play and experimentation, on the body or mannequin, and in the prototyping through digital tools. Often these activities were group-based and involved form-giving across disciplines (textiles, technology, product, fashion), thus, there was a convergence of disciplinary thinking and practices, which set the foundation for shared understanding through new networks. The main observed difference across the projects was the degree of resolution, and in most cases this is where the projects reached natural endpoints as provocations and research insights. As an exception, the Design Specks project had a more resolved outcome, as discussed in the context of the intersecting design-led practices in the co-design of wearables.

\section{Discussion}

$>$ REFLECT: Why is an intersecting set of design-led practices important in the development of new wearables?

MIT was an exercise in working with textile thinking and embedding a narrative, thus low fidelity textile-based making was the central objective. It was an open, explorative workshop to determine whether there were opportunities to embed technology into textiles - that objective was specifically to look at the material constructs of technology alongside traditional and emergent ways of making. While new applications for technology were a key driver of this project, materiality and making were central - thus it sought to inform how tacit engagement in ideas could inform future technical textiles (Figure 5).

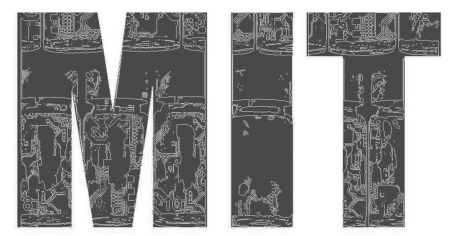

\section{Molecular Imprinted Textîiles}

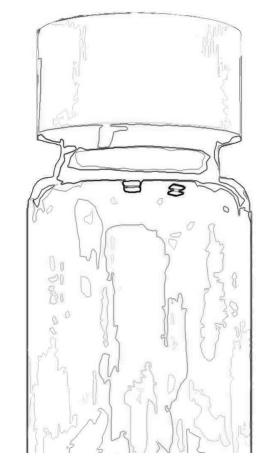

Figure 5. Textile materialisations as a means to capture and explore technological narratives in the Molecular Inspired Textiles (MIT) project.

It is as important to bring different design disciplines and their respective working methods together (in this case, Fashion and Textiles and Product Design) as it is to realize the new applications for technology. The dynamics of a group is always an unknown, particularly when bringing together Academics from Health and Social Sciences, Technology and Design, with User-groups and Industry. Thus, co-design workshops can facilitate an understanding of the importance of embedding empathic value in the design outcomes for the end user/wearer. The premise for FTV was to allow Industry to drive the enquiry into future applications, so a blue-sky approach, with Industry informing the starting point, did not achieve the initial 'lift' required to achieve speculative design ideas. Second Skin, in contrast, focussed more on empathic design 
approaches and the realisation of product development through digital fabrication to accelerate commercial opportunities. This was seen as possible, based on the use of accessible and personal scenarios that helped idea generation even in the early stages of product concepts. As such, when positioned by design, technology could be the medium that required all participants to focus and challenge their efforts beyond conceiving to achieve tangible working prototypes in a very short time frame, in this case one day.

In pushing forward to Design Specks and the $S^{* * *}$ word, we explored the possibilities for a greater reciprocity between the culture of the wearer and the concept of user and product function. Figure 6 reveals a functional prototype realised over a longer-development period, which was tested and reaffirmed by a continual refinement and live-dialogue between designers, users and technology. Driving this work to a fina public exhibition and published book of the collaborative 'Design Specks' works, meant that ideas were fully formed and exhibited as readily resolved near-consumer products.
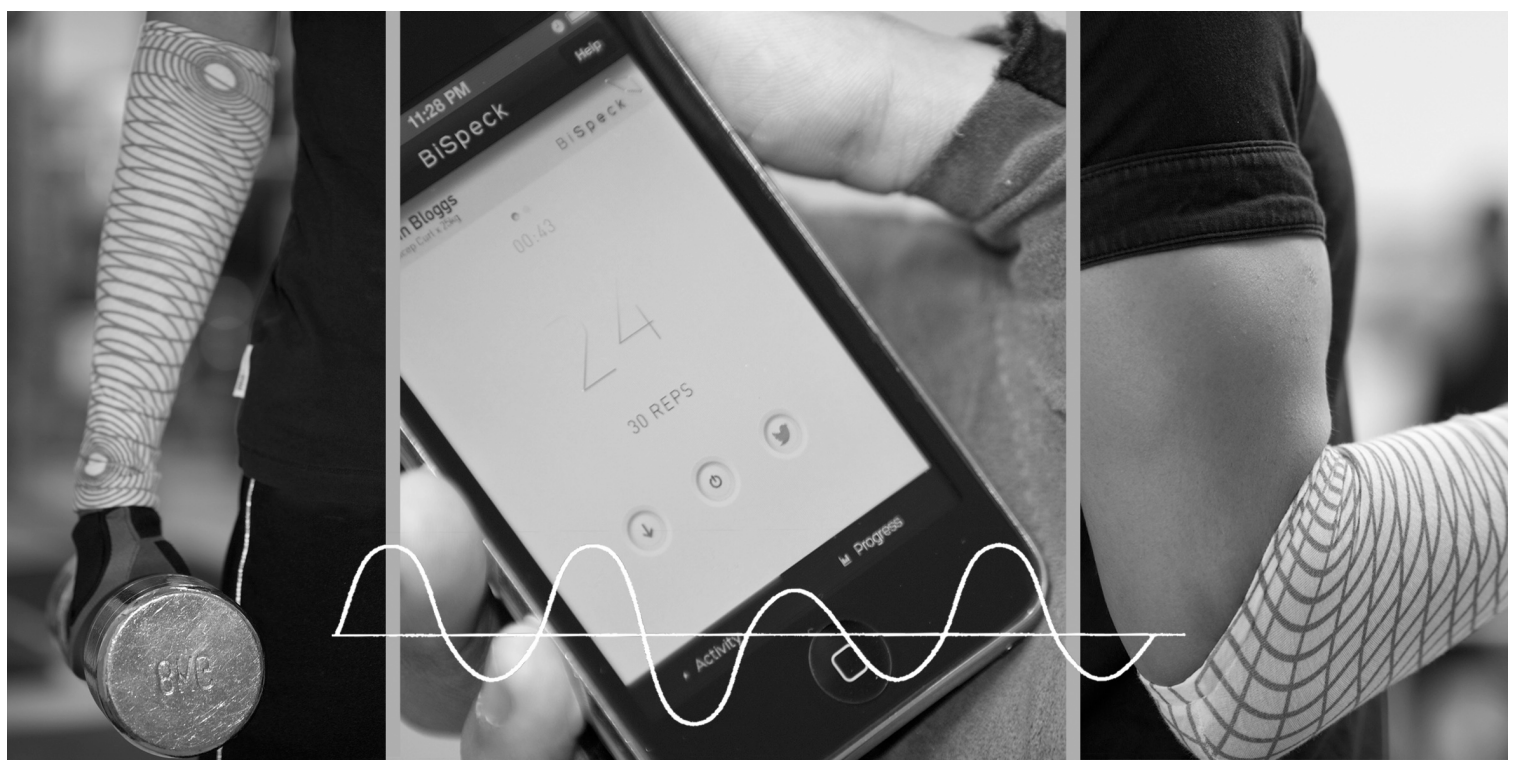

Figure 6. BiSpeck: a functional prototype for a digitally printed fitness wearable that captures motion and effort with an accompanying application - exhibited as part of the Design Specks Exhibition, June 2013 at Inspace Gallery, Edinburgh.

In returning to the original focus of this paper, we propose that by focusing more on empathic methodologies and material exploration, there was greater opportunity to explore context and to encourage those from fashion and textile design disciplines to develop empathic aspects - to explore what it means to be 'that wearer'. Finding ways to operate together in a new sphere of practice, where co-design driven prototyping requires us to develop a shared understanding is what ultimately informs the realisable objectives of this practice.

The authors offer a new working methodology (Figure 7), whereby spheres of practice foster the transformative nature of intersecting methodologies, bringing together technology and materiality. It is a means to address disconnects between Design, Academia and Industry; between Design and Technology (both digital and analogue); and between wearer and user - thus addressing one of the biggest barriers to the development of innovative wearables. 


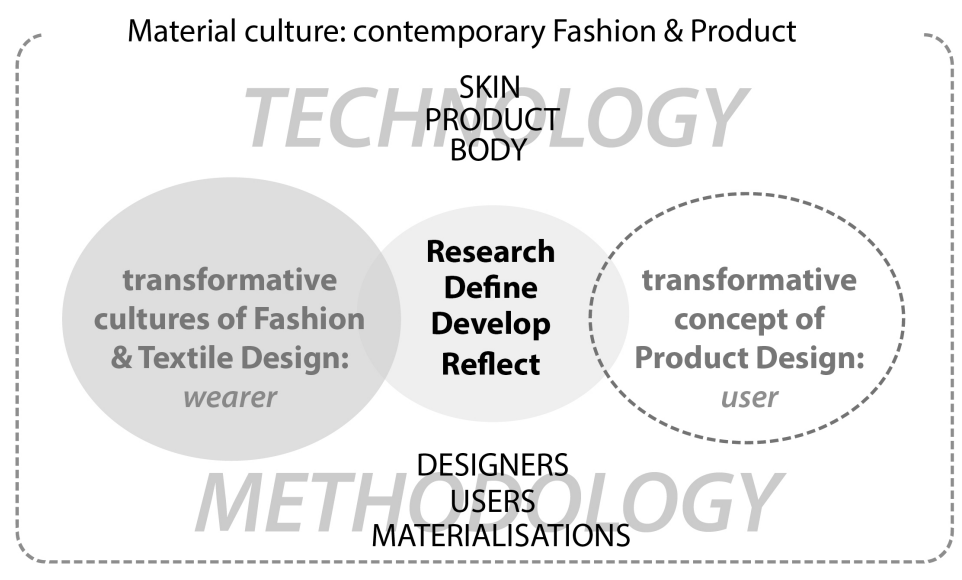

Figure 7. A graphical representation of a new working space for the co-design of wearables (visualisation by J. Pengelly).

The authors now propose to apply this methodology to scope future research, which will seek not only to create new solutions and perspectives that bring us back in touch with our emotional and empathic intelligence and towards a softer future, but will also focus on defined outcomes which will engage industry in new conversations.

\section{References}

Arvind, DK., Duplock, P., Fairburn, S. Oliver, R., Stricevic, M., and Verhoeven, A. 2013. Design Specks: Connecting People with Speckled Computing, pp. 17-58. Dundee: Winter and Simpson Print.

Baurley, S. and Stead, L. 2007. The Emotional Wardrobe, "Chapter" in Inns, T. (ed.) Designing for the $21^{\text {st }}$ Century: Interdisciplinary Questions and Insights, pp. 273-298. London: Gower Ashgate.

Beucker, N. 2015. Transformational design: A Piecemeal Situational Change, "Chapter" in Jonas, W. (ed.), Zerwas, S. (ed.) \& von Anshelm, K. (ed.) Transformation Design Perspectives on a New Design Attitude, pp. 33-42. Berlin, Basel: Birkhäuser.

Burns, C., Cottam, H., Vanstone, C., and Winhall, J. 2006. RED paper 02: Transformation design. London: Design Council.

Brown, T. 2008. Design Thinking. Harvard business review, 86(6): 84 - 92.

Bugg, J. 2009. Fashion at the Interface: Designer-Wearer-Viewer, Fashion Practice. The Journal of Design, Creative Process \& the Fashion Industry, 1(1): 9-31.

Carroll, J. M. 2000. Five reasons for scenario-based design. Interacting with Computers, 13(1): 43-60.

Congdon, A. 2015. Website, $6^{\text {th }}$ October 2016.

Dieffenbacher, F. 2013. Fashion Thinking: Creative Approaches to the Design Process. pp.10-11. London: Bloomsbury Publishing.

Dunne, A. and Raby, F. 2013. Speculative Everything. Design, Fiction and Social Dreaming. pp.69 - 88. Cambridge, Massachusetts: The MIT Press.

Dunne, L. 2010. Beyond the second skin: an experimental approach to addressing garment style and fit variables in the design of sensing garments. International Journal of Fashion Design, Technology and Education, 3(3): 109-117.

Dunne, L. 2010. Smart Clothing in Practice: Key Design Barriers to Commercialization. Fashion Practice, The Journal of Design, Creative Process \& the Fashion, 2(1): 41-66.

Gwilt, A. 2013. Valuing the Role of the Wearer in the Creation of Sustainable Fashion. Research Journal of Textile and Apparel, 17 (1): $78-86$. 
Haldane, J. 2014. Speculative Design: Playing Devil's Advocate. The Architectural Review. Website, $6^{\text {th }}$ October 2016.

Hildebrandt, J., Brauner, P. and Ziefle, M. 2015. Smart Textiles as Intuitive and Ubiquitous User Interfaces for Smart Homes: Human Aspects of IT for the Aged Population. Design for Everyday Life. Volume 9194 of the series Lecture Notes in Computer Science pp 423-434. Switzerland: Springer Publishing.

Hummels, C. and Frens, J. 2008. Designing for the unknown: A design process for the future generation of highly interactive systems and products. In: A. Clarke, M. Evatt, P. Hogarth, J. Lloveras and L. Pons. New perspectives in Design Education Volume 1. Proceedings of the 10th International Conference on Engineering and Product Design Education, Barcelona: Spain.

Igoe, E. 2010. The tacit-turn: textile design in design research In Duck Journal for Research in Textiles and Textile Design, (1):1-11.

Jarche, H. 2010 Networked learning Model. Website, $6^{\text {th }}$ October 2016.

Koskinen, I., Battarbee, K. and Mattelma“ki, T. 2003 (eds.), Empathic Design. User Experience for Product Design. IT Press: Helsinki.

Lovell, S. 2011. Dieter Rams: As Little Design As Possible, Phaidon Press. London.

Lynas, E. 2010. Textiles, Connection and Meaning, in Fashion: Sustainability and Creativity, Commodore Vijay Chaturvedi (ed.), Conference Proceedings (IFFTI) pp. 61-70.Taipei: Taiwan.

Make, B. and Tilbury, N. 2014. Website. $6^{\text {th }}$ October 2016.

McDonagh, D. and Formosa, D. 2008. Designing for Everyone, One Person at a Time in The Silver Market Phenomenon, Kohlbacher, F and Herstatt, C. (eds.) pp.91-100, Springer Verlag: Berlin.

McDonagh, D., Thomas, J., Chen, S., He, J., Hong,Y., Yunjin Kim, Zhang, Z., and Pena- Mora, F. 2009 Empathic Design Research: Disability + Relevant Design, pp. 310-315, European Academy of Design Conference, EAD09/040.

Moar, J. 2014. Fit for the Future with Wearables. White Paper. Hampshire: Juniper Research Ltd. Website, $6^{\text {th }}$ October 2016.

Mottram, J. 2004. Textile fields and workplace emotions. "Chapter" in McDonaugh, D, Hekkert, P, van Erp, J \& Gyi, D (eds.) Design and Emotion. The Experience of Everyday Things. pp. 53-57, London: Taylor \& Francis

Norman, D, A. 2002. Emotion and Design: Attractive things work better, Interactions Magazine, 4(4): 36-42.

Oliver, R., Tillotson, J. and Toomey, A. 2009) Bioengineered Textiles and Nonwovens - The Convergence of Biominiaturisation and Electroactive Conductive Polymers for Assistive Healthcare, Portable Power and Design-led wearable Technology. Journal of Fibre Bioengineering and Informatics, 2 (1): 1-13.

O’Mahoney, M. 2011. Advanced Textiles for Health and Wellbeing: London: Thames \& Hudson Ltd.

Potts, C. 1995. Using schematic scenarios to understand user needs. In: DIS'95: ACM Symposium on Designing Interactive Systems, pp. 247-256. Ann Arbor, MI. ACM Press: New York.

Rosenberg, D. 2014. Transformational Design: A New Operational Framework and Model for Experience Design. Website, $6^{\text {th }}$ October 2016.

Ryan, S., 2014. Garments of Paradise: Wearable Discourse in the Digital Age: Cambridge: MIT Press.

Sangiorgi, D. 2011. Transformative Services and Transformation Design. International Journal of Design, 5(2), 29-40 Schuler, D. \& Namioka, A. (eds). 1993. Participatory Design: Principles and Practices. Hillsdale: Lawrence Earlbaum Associates.

Skogsrød, I, Ø. 2014. Empathy and Aesthetics: Combating Stigma in the Design of Assistive Products. $6^{\text {th }}$ October 2016.

Stead, L. 2005. The Emotional Wardrobe. A Fashion Perspective on the Integration of Technology and Clothing. London: The University of the Arts London. PhD Thesis. $6^{\text {th }}$ October 2016.

Steed, J., Fairburn, S. 2016. Second Skin Iterations: Programmes and Prototypes: Proceedings of the Futurescan3: Intersecting identities, Association of Fashion \& Textile Courses (FTC).

Wilkinson C.R., De Angeli A. 2014. Applying user centred and participatory design approaches to commercial product development, Design Studies, 35(6):614-631. 
Woolley, M. 2005. The Product Unplugged - Towards a Pervasive Digital Design. In: Proceedings of the International Design Conference - IASDR 2005, National Yunlin University of Science and Technology, College of Design: Taiwan. 


\begin{tabular}{|l|l|}
\hline Table 1 & $\begin{array}{l}\text { An overview of project practices across the design process, aligned to Wearers and Users } \\
\text { (shading denotes approaches that are in shaded cells are discussed in further detail). }\end{array}$ \\
\hline Figure 1 & $\begin{array}{l}\text { A working framework for mapping the spheres of co-design methodologies aligned to } \\
\text { wearer and user. }\end{array}$ \\
\hline Figure 2 & $\begin{array}{l}\text { FTV Opportunities Map of Workshop Participants (classified as industry or academic) } \\
\text { showing their focus at the outset of the workshop and over the course of the day, as } \\
\text { indicated by arrows. (Image source S. Fairburn). }\end{array}$ \\
\hline Figure 3 & $\begin{array}{l}\text { A capture of the MIT workshop activity showing how tacit knowledge of materials was } \\
\text { aligned to new applications of technology. (Image source J. Steed). }\end{array}$ \\
\hline Figures 4a, b & $\begin{array}{l}\text { Functional Prototyping: 4a: Digital knitting designs for the under-wardrobe project at the } \\
\text { Politecnico di Milano (S*** Word) and 4b: 3D-printing design concepts at MAKLab Glasgow } \\
\text { (Second Skin). }\end{array}$ \\
\hline Figure 5 & $\begin{array}{l}\text { Textile materialisations as a means to capture and explore technological narratives in the } \\
\text { Molecular Inspired Textiles (MIT) project. }\end{array}$ \\
\hline Figure 6 & $\begin{array}{l}\text { BiSpeck: a functional prototype for a digitally printed fitness wearable that captures motion } \\
\text { and effort with an accompanying application - exhibited as part of the Design Specks } \\
\text { Exhibition, June 2013 at Inspace Gallery, Edinburgh. }\end{array}$ \\
\hline Figure 7 & $\begin{array}{l}\text { A graphical representation of a new working space for the co-design of wearables } \\
\text { (Visualisation by J. Pengelly). }\end{array}$ \\
\hline
\end{tabular}

